\title{
BMJ Open Quality Reducing inappropriate outpatient antibiotic prescribing: normative comparison using unblinded provider reports
}

Richard V Milani, Jonathan K Wilt, Jonathan Entwisle, Jonathan Hand, Pedro Cazabon, Jefferson G Bohan

To cite: Milani RV, Wilt JK, Entwisle J, et al. Reducing inappropriate outpatient antibiotic prescribing: normative comparison using unblinded provider reports. BMJ Open Quality 2019;8:e000351. doi:10.1136/ bmjoq-2018-000351

Received 6 February 2018 Revised 3 January 2019 Accepted 4 January 2019

\section{Check for updates}

(c) Author(s) (or their employer(s)) 2019. Re-use permitted under CC BY-NC. No commercial re-use. See rights and permissions. Published by BMJ.

Center for Healthcare Innovation, Ochsner Health System, New Orleans, Louisiana, USA

Correspondence to Dr. Richard V Milani; rmilani@ochsner.org

\section{ABSTRACT}

Importance Antibiotic resistance is a global health issue. Up to $50 \%$ of antibiotics are inappropriately prescribed, the majority of which are for acute respiratory tract infections (ARTI).

Objective To evaluate the impact of unblinded normative comparison on rates of inappropriate antibiotic prescribing for ARTI.

Design Non-randomised, controlled interventional trial over 1 year followed by an open intervention in the second year.

Setting Primary care providers in a large regional healthcare system.

Participants The test group consisted of 30 primary care providers in one geographical region; controls consisted of 162 primary care providers located in four other geographical regions.

Intervention The intervention consisted of provider and patient education and provider feedback via biweekly, unblinded normative comparison highlighting inappropriate antibiotic prescribing for ARTI. The intervention was applied to both groups during the second year.

Main outcomes and measures Rate of inappropriate antibiotic prescription for ARTI.

Results Baseline inappropriate antibiotic prescribing for ARTI was $60 \%$. After 1 year, the test group rate of inappropriate antibiotic prescribing decreased $40 \%$, from $51.9 \%$ to $31.0 \%(p<0.0001)$, whereas controls decreased $7 \%(61.3 \%$ to $57.0 \%, p<0.0001)$. In year 2 , the test group decreased an additional $47 \%$ to an overall prescribing rate of $16.3 \%$, and the control group decreased $40 \%$ to a prescribing rate of $34.5 \%$ after implementation of the same intervention.

Conclusions and relevance Provider and patient education followed by regular feedback to provider via normative comparison to their local peers through unblinded provider reports, lead to reductions in the rate of inappropriate antibiotic prescribing for ARTI and overall antibiotic prescribing rates.

\section{INTRODUCTION}

Antimicrobial drug resistance among common bacterial pathogens is now a federal and global health crisis. ${ }^{1-3}$ According to the Centers for Disease Control and Prevention (CDC), at least 2 million illnesses and 23000 deaths in the USA are caused by antibiotic resistant bacteria. ${ }^{4}$ If this trend persists, it is estimated by 2050 , there will be 10 million antimicrobial resistance deaths worldwide, costing the world up to $\$ 100$ trillion. $^{5}$

Antibiotics for acute respiratory tract infections (ARTI) in the outpatient setting account for almost half (44\%) of the more than 266 million antibiotic prescriptions written each year in the USA, and is a major contributor to antimicrobial resistance. ${ }^{67}$ It is estimated that approximately half of these prescriptions are inappropriate, given for conditions for which antibiotics provide no benefit. ${ }^{8}$ In addition to increasing the prevalence of antibiotic-resistant bacteria, overuse of antibiotics exposes patients to the unnecessary risk of adverse drug events. In fact, antibiotics are the leading cause of adverse drug events accounting for nearly $24 \%$ of adverse drug events present on admission. ${ }^{9}$

In 2015, the White House released the National Action Plan for Combating Antibiotic-Resistant Bacteria, targeting a $50 \%$ reduction of inappropriate antibiotic prescribing in the outpatient setting by $2020 .^{3}$ In addition, numerous society guideline recommendations and clinical studies have been published alerting providers to the problems associated with antibiotic overuse, yet overuse persists. ${ }^{6}{ }^{10}$ Over the period from 2010 to 2015 , the USA spent $\$ 56$ billion on antibiotics of which the majority $(59.1 \%)$ were in the outpatient setting. As such, primary care and emergency departments remain optimal sites for antibiotic stewardship interventions. ${ }^{11}$

Physicians are generally motivated to provide care that promotes patient well-being and professional standards, and successful changes to clinical practice often involve strategies that encourage physicians to practice high-value care. ${ }^{12}$ One promising approach uses social comparisons to provide physicians 
with individual feedback comparing their performance relative to that of their local peers. ${ }^{13} 14$ In the outpatient setting, this approach has been used as an effective tool to reduce inappropriate antibiotic usage.$^{1516}$ To date, previously published interventions in antibiotic prescribing in the outpatient setting have focused on providing blinded data to other providers, where they may be listed as a top or bottom performer without explicit knowledge of how specific colleagues perform in relation to themselves. ${ }^{15}$ The use of unblinded data, where each colleague's performance is revealed, further elicits the social and behavioural aspect of prescribing, is novel and promotes transparent practice.

We evaluated the use and feasibility of patient education combined with normative comparison with unblinded feedback among primary care physicians in a large clinical practice, as a means of reducing inappropriate outpatient antibiotic prescribing for ARTI.

\section{METHODS}

The study site was a large regional healthcare system (Ochsner Health System) that employs 192 primary care providers (PCPs) consisting of physicians and advanced practice providers, located in ambulatory settings covering five large geographical regions in southeast Louisiana. Each region employs approximately 20-40 PCPs who are in regular contact with other intraregional PCP's, but are in less frequent contact with PCPs outside of their geographical region. One geographical region was randomly chosen as the initial test region with the remaining regions serving as initial control in order to test the acceptance and evaluate the response to the intervention. The first intervention took place over a 10-month period (March 2016-December 2016) and displayed the inappropriate antibiotic prescribing rate where the denominator was the total number of patients seen with an ARTI as the primary diagnosis without a concomitant reason for antibiotic prescribing, and the numerator was the total number of such patients that received an antibiotic order during that visit. Following proof of concept, the same intervention was applied to the remaining geographical regions (control group) for 1 year (January 2017-December 2017) to evaluate widespread acceptance and effectiveness.

The primary outcome was the antibiotic prescribing rate for antibiotic-inappropriate ARTI visits in adult patients ( $\geq 18$ years) with no concomitant reason for antibiotic prescribing. Antibiotic-inappropriate diagnoses included non-specific upper respiratory tract infections, acute bronchitis and influenza (International Classification of Diseases, Ninth Revision codes 460, 464, 464.0, 464.00, 464.1, 464.10, 464.2, 464.20, 464.4, 464.50, 465, 465.0, 465.8, 465.9, 466, 466.0, 466.1, 466.11, 466.19, 487, 487.1, $487.8,490) .{ }^{15}$ The evaluation of rates of inappropriate prescribing was measured by the number of times an electronic order for an antibiotic corresponded to one of the antibiotic-inappropriate diagnoses during a primary care visit encounter within the electronic medical record (Epic Systems).

\section{Intervention}

Each provider attended a regularly scheduled regional meeting that reviewed operational and clinical issues impacting their practice. At this meeting, the antibiotic stewardship intervention was added to the other operational issues on the agenda. Mean regional rates of inappropriate antibiotic prescribing were displayed and the clinical rationale for reducing inappropriate antibiotic usage was presented. Each PCP received evidencebased guidelines for the management of ARTI, as well as a pocket guide displaying the recommended management algorithm. ${ }^{17-19}$ Posters from the CDC's Get Smart programme ('Viruses or Bacteria What's got you sick?') along with the CDC's Get Smart 'Virus prescription pads' and 'Cold or Flu. Antibiotics Don't Work for You' brochures were handed out. ${ }^{20}$ Providers were told that these would be placed in their waiting rooms and examination rooms in the next several days. Additionally, a mock peer comparison sample card was provided, and ample time was provided for questions.

Normative peer comparison was made by an email report sent to each PCP every 2 weeks generated from the electronic medical record. PCPs were ranked from lowest to highest inappropriate prescribing rates (best to worst) within the test region. The initial email was a blinded ranking revealing only the emailed practitioner's individual rank compared with his/her local peers; all subsequent reports were fully unblinded, such that each practitioner was aware of his/her ranking as well as detailed feedback as to the prescribing patterns and rankings of other named PCPs in their practice. Each email read as follows:

'Antibiotic overuse leads to unnecessary adverse drug effects and antimicrobial-resistant infections, which harm patients. As part of an ongoing Antibiotic Stewardship Program we are reporting antibiotic overuse based on Healthcare Effectiveness and Information Set (HEDIS) criteria.

Please see below for your Antibiotic Prescribing Rate for Antibiotic-Inappropriate Acute Respiratory Tract Infection visits and no concomitant reason for antibiotic prescribing for the current calendar year. The antibiotic order rate denominator is the total number of patients seen by you where an Acute Respiratory Infection diagnosis was used as the primary encounter diagnosis, and the numerator is the total number of those patients that received an antibiotic order during that visit. This metric summarizes the rate between you and your peers based on the current guideline recommendations for inappropriate use of antibiotics in acute respiratory infection. National studies show best in class to be under $5 \%$.' https://www.cdc.gov/getsmart/community/improvingprescribing/outpatient-stewardship.html.

To ensure providers did not modify visit diagnoses to avoid detection of inappropriate prescriptions, we also 
Table 1 Characteristics of providers in the test and control groups

\begin{tabular}{|c|c|c|c|}
\hline Characteristic & $\begin{array}{l}\text { Test group } \\
(n=30)\end{array}$ & $\begin{array}{l}\text { Control group } \\
(n=162)\end{array}$ & $P$ value \\
\hline Age (years) (SD) & $40 \pm 12$ & $45 \pm 12$ & 0.05 \\
\hline Females (\%) & 17 (57\%) & 89 (55\%) & NS \\
\hline MD/APP ratio & 2.3 & 2.1 & NS \\
\hline $\begin{array}{l}\text { Average clinic visits/ } \\
\text { provider/year (SD) }\end{array}$ & $2610 \pm 1271$ & $2509 \pm 1169$ & NS \\
\hline $\begin{array}{l}\text { Average upper respiratory } \\
\text { tract infection visits/ } \\
\text { provider/year (SD) }\end{array}$ & $123 \pm 95$ & $116 \pm 96$ & NS \\
\hline $\begin{array}{l}\text { Baseline inappropriate } \\
\text { antibiotic prescription rate }\end{array}$ & $51.9 \%$ & $61.3 \%$ & $<0.0001$ \\
\hline
\end{tabular}

APP, advanced practice provider; MD, medical doctor; NS, nonsignificant.

tracked the percentage of visits with respiratory tract infection diagnoses (either as a primary diagnosis or as any diagnosis) as well as all visits where an antibiotic was prescribed.

\section{Statistical analysis}

Statistical analysis was performed using SPSS V.16.0. Results are expressed as mean $\pm \mathrm{SD}$, or as $\mathrm{n}(\%)$ where appropriate. Analysis of differences between groups was performed using Student's t-test for continuous variables, $\chi^{2}$ test for categorical variables and analysis of variance for differences among frequencies for several groups. In all analyses, two-sided $\mathrm{p}<0.05$ was considered significant.

\section{RESULTS}

One hundred and ninety-two PCPs were evaluated with an average age of $44 \pm 12$ years $(55 \%$ female, 133 physicians/59 advanced practice providers). Baseline inappropriate antibiotic prescribing for the entire cohort was $59.6 \%$ (range $0 \%-100 \%$ ).
There were 30 PCPs in the test group and 162 PCPs in the control group. The test group was slightly younger ( $40 \pm 12$ vs $45 \pm 12$ years; $\mathrm{p}=0.05)$ and had a lower baseline rate of antibiotic usage $(51.9 \%$ vs $61.3 \%, \mathrm{p}<0.001)$ compared with controls (table 1).

Following 1 year of biweekly reports providing normative comparison among the test group, inappropriate antibiotic usage decreased $40 \%$, from $51.9 \%$ to $31.0 \%$ $(\mathrm{p}<0.0001)$, whereas the control group decreased $7.0 \%$ $(61.3 \%$ to $57.0 \%, \mathrm{p}<0.001)$.

The test group was further divided into those who were responsive to the intervention (relative reduction in inappropriate antibiotic prescribing by at least $20 \%$ from baseline or achieving an absolute follow-up rate below 30\%) or unresponsive to the intervention. Twenty-six $(87 \%)$ PCPs in the test group were classified as responders to the normative comparison intervention, and their inappropriate prescribing rate fell from $44 \%$ to $19 \%(\mathrm{p}<0.0001)$ (figure 1). In contrast, the $4(13 \%)$ providers categorised as non-responders had no change from the intervention (inappropriate antibiotic usage increased from $78 \%$ to $84 \%$, $(\mathrm{p}=\mathrm{NS})$ ). Responders were younger (age $38 \pm 9$ vs $60 \pm 17$ years; $\mathrm{p}=0.002$ ) but otherwise had no other significant differences from non-responders including gender, visit volume or provider type (physician vs non-physician).

Visits with respiratory tract infection diagnoses (either as a primary diagnosis or as any diagnosis) as well as all visits where an antibiotic was prescribed is shown in figure 2. The data demonstrate that total antibiotic prescriptions diminished during the intervention periods (table 2). Moreover, the frequency of respiratory tract infection diagnoses remains unchanged from the previous year.

Following proof of acceptance among PCPs, the intervention was extended in year 2 to the control group, and continued in the initial test group. The test group's prescription of inappropriate antibiotics for ARTI fell an additional $47 \%$ compared with year 1 , to an absolute rate

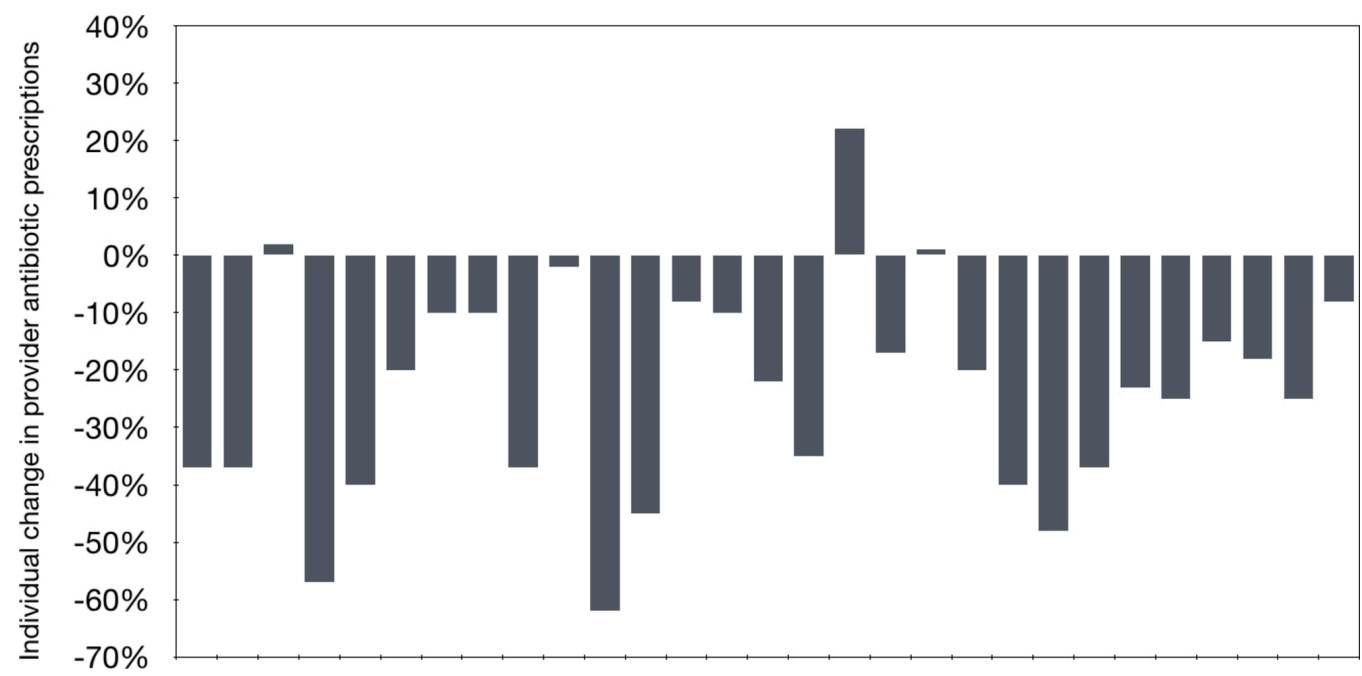

Figure 1 Change in test group individual prescribing of inappropriate antibiotics during the first year of the intervention. 
A

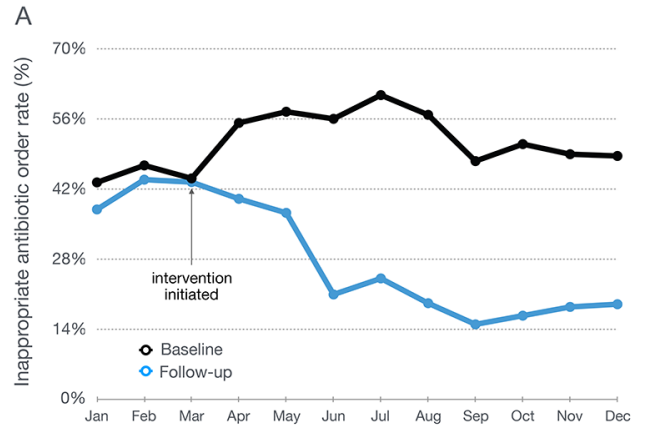

C

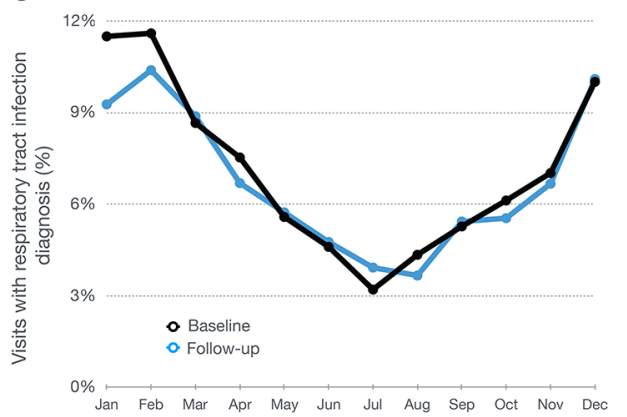

B

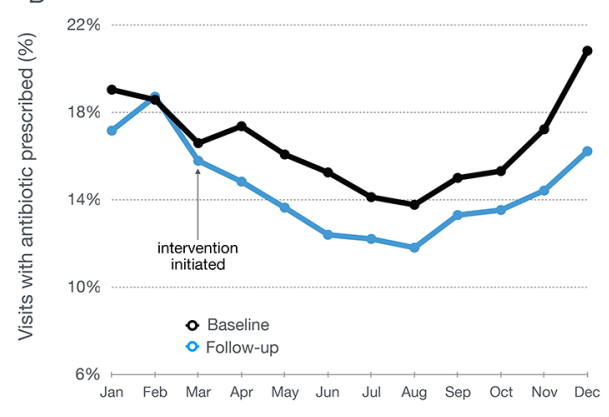

D

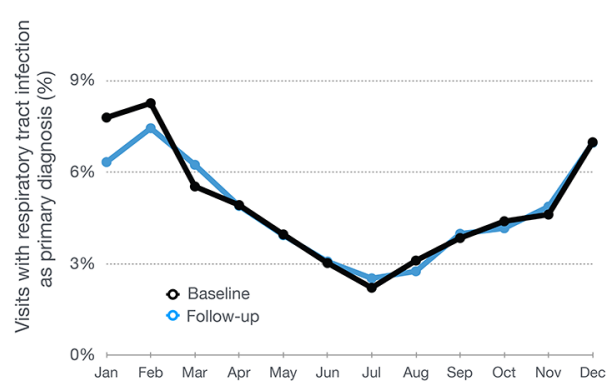

Figure 2 Visit and provider characteristics of the test group over one calendar year. (A) Rate of inappropriate prescription of antibiotics for respiratory tract infections. (B) Total rate of antibiotics prescribed per encounter visit for all conditions. (C) Percentage of encounter visits with any diagnosis of respiratory tract infection. (D) Percentage of encounter visits with the primary diagnosis of respiratory tract infection.

of $16.3 \% \quad(p<0.001)$. Following 1 year of exposure to the intervention, the control group fell $40 \%$ to an absolute rate of $34.5 \%(\mathrm{p}<0.001)$ (table 2$)$.

\section{DISCUSSION}

There are two important findings from this investigation. First, combining provider and patient education with regular feedback in the form of unblinded normative comparison with local peers results in marked improvement in the inappropriate prescription of antibiotics for ARTI in the primary care setting. Second, almost $90 \%$ of providers were shown to be responsive to this method of behaviour change.

Three key components of the intervention likely influenced the outcome. First, provider education was

\begin{tabular}{lllll}
\hline Table 2 & \multicolumn{4}{l}{ Change in antibiotic prescribing over time } \\
\hline Group & $\begin{array}{l}\text { Antibiotic } \\
\text { prescribing }\end{array}$ & $\begin{array}{l}\text { Baseline, Year } \mathbf{1}^{*}, \\
\text { \% }\end{array}$ & $\begin{array}{l}\text { Year 2+, } \\
\text { \% }\end{array}$ \\
\hline Test & $\begin{array}{l}\text { Inappropriate rate } \\
\text { for ARTI }\end{array}$ & 51.9 & 31.0 & 16.3 \\
Test & $\begin{array}{l}\text { Total antibiotic rate } \\
\text { all conditions }\end{array}$ & 17.5 & 15.2 & 12.3 \\
Control & $\begin{array}{l}\text { Inappropriate rate } \\
\text { for ARTI }\end{array}$ & 61.3 & 57.0 & 34.5 \\
Control & $\begin{array}{l}\text { Total antibiotic rate } \\
\text { all conditions }\end{array}$ & 14.8 & 14.4 & 11.9 \\
\hline
\end{tabular}

*Intervention limited to test group.

†Intervention in both test and control groups.

ARTI, acute respiratory tract infection. delivered in the form of up-to-date guideline recommendations, educational videos, and pocket guides regarding the evidence-based management of ARTI. Second, providers were assisted with patient education and expectations both prior to, and at the time of, the clinic encounter. Posters placed in patient waiting areas conveying that 'antibiotics aren't always the answer', reset patient expectations prior to their clinical encounter. In the examination room, patient brochures and a virus prescription pad allowed patients to leave with something in hand specifically addressing their viral condition, while providing reinforcement supporting the physician's decision to avoid antibiotics. Importantly, these messages were delivered under the auspices of the US Department of Health and Human Services, and the CDC, further validating the provider's recommendation. Third, and most importantly, the use of normative influence by way of biweekly, unblinded reports provided a broader perspective to each providers' practices.

Although patient education in the form of printed materials used in the waiting and examination rooms was a component of the intervention, this intervention alone has generally been ineffective at modifying patient behaviour and altering patient outcomes. ${ }^{21}$ However, interventions that use provider and patient education combined with provider insights as to their rate of inappropriate antibiotic prescribing have been successful in reducing rates of inappropriate antibiotic prescribing. Combined with education, Gjelstad et al demonstrated a reduction in antibiotic prescribing (OR 0.72) for ARTI compared with controls following a one-time display of a practitioner's 
prescribing profile from the preceding year. ${ }^{22}$ Meeker et al tested multiple behavioural interventions in primary care practices to evaluate which achieved the greatest efficacy in reducing inappropriate antibiotic prescribing for ARTI. Both accountable justification at the time of prescribing as well as regular reports displaying blinded peer comparison resulted in the lowest rates of inappropriate antibiotic prescribing. ${ }^{15}$ A clear advantage of peer comparison over accountable justification is that it adds no additional work for the provider during the clinical encounter. Our study was unique in that it provided regular unblinded reports to all PCPs within our health delivery system and was markedly successful at a system level. In such an environment, unblinded peer performance information may facilitate developing a group norm around which individual physicians can anchor their own performance. Although providers may be uncomfortable with the local colleagues seeing their individual performance scores, unblinded data may better support peer-based learning. ${ }^{23}$

Providers are motivated to administer care that encompasses the current evidence while improving patient wellbeing. Moreover, individuals often conform to fulfil peer expectations and gain acceptance, particularly if the behaviour aligns with professional standards. ${ }^{12} 1424$ The unblinded nature of the reports aided in generating conformity towards an evidence-based goal, in keeping with professional standards and patient's best interest. In addition, physicians often make different decisions when managing individual patients versus viewing groups of patients from a population-based perspective. Specifically, physicians have been shown to give more weight to a patient's personal concerns when they consider the patient as an individual and more weight to general criteria of effectiveness when they consider the patient as part of a group or population. ${ }^{25}$ By viewing biweekly reports of their antibiotic decisions in aggregate, physicians modified their behaviour as a result of this new population-based perspective..$^{26}$ Interestingly, our study also found that providers who responded to the intervention were significantly younger compared with those who did not. One possible explanation for this is providers may have long-standing patient relationships in which they feel uncomfortable changing practice for fear of a perceived 'lack of consistency'. Additionally, it is sometimes difficult to change a long-held practice pattern even when new scientific evidence is available. ${ }^{27}$ Similarly, the CDC recently reported southern, male primary care physicians aged 40 years and older prescribed more antibiotics than specialty-matched peers. ${ }^{28}$ The barriers to such practice change need to be further evaluated.

It is worth commenting that generating and operationalising this intervention is inexpensive in the context of a comprehensive electronic medical record system. Moreover, continuation of the intervention can take place for any desired duration by creation of automated reports.

Finally, the clinical and financial impact of these changes can be significant. Adverse drug events increase the risk of death, length of hospitalisation, emergency department utilisation and overall cost of care, and antibiotics are the leading cause, representing nearly $24 \%$ of adverse drug events present on admission. ${ }^{9}$ In the second year of the intervention, across all primary care practices, we avoided prescribing an estimated 16589 unnecessary antibiotics. The estimated savings include approximately $\$ 751664$ in antibiotic costs (average wholesale price) and further avoided an estimated 3318 adverse drug events costing an estimated $\$ 5447796 .^{29-34}$

\section{Limitations}

First, this was a single-centre study, and our results may not be applicable to other practice settings. Second, there were significant baseline differences in the rate of inappropriate antibiotics prescribed, between test and control groups. This may suggest that the test group was more amenable to the intervention than other providers, but the degree of impact in the control group in year 2 suggests otherwise. Third, we did not qualitatively evaluate the thoughts and attitudes of providers who did not respond to the intervention. Further assessment of these outliers may lead to optimisation of similar normative comparison initiatives in the future. Fourth, the intervention consisted of three components together, and we cannot discern the individual impact of each one. Finally, we do not know the durability of the intervention over time, and this will require further study.

\section{CONCLUSION}

A comprehensive programme consisting of provider and patient education, followed by regular feedback using normative comparison with local peers, markedly reduces the rate of inappropriate antibiotic prescribing for patients with ARTI resulting in an overall decrease in outpatient antibiotic prescriptions. The results have significant implications in combating antibiotic resistance as well as modelling physicians towards quality and safety goals.

Contributors RVM: planning, writing, overall content as guarantor. JKW: analysis. JE: conducting survey/report cards, analysis. JH: conducting study protocol, writing. PC: conducting study protocol. JGB: conducting study protocol, writing.

Funding The authors have not declared a specific grant for this research from any funding agency in the public, commercial or not-for-profit sectors.

Competing interests None declared.

Patient consent for publication Not required.

Provenance and peer review Not commissioned; externally peer reviewed.

Data sharing statement № additional data are available.

Open access This is an open access article distributed in accordance with the Creative Commons Attribution Non Commercial (CC BY-NC 4.0) license, which permits others to distribute, remix, adapt, build upon this work non-commercially, and license their derivative works on different terms, provided the original work is properly cited, appropriate credit is given, any changes made indicated, and the use is non-commercial. See: http://creativecommons.org/licenses/by-nc/4.0/.

\section{REFERENCES}

1. Spellberg B, Blaser M, Guidos RJ, et al. Combating antimicrobial resistance: policy recommendations to save lives. Clin Infect Dis 2011;52(Suppl 5):S397-428.

2. U.S. Department of Health and Human Services. Presidential Advisory Council on Combating Antibiotic-Resistant Bacteria. 2015 
https://www.hhs.gov/ash/advisory-committees/paccarb/aboutpaccarb/index.html (Accessed 9 Dec 2017).

3. The White House. National action plan for combating antibioticresistant bacteria. $2015 \mathrm{https}: / / w w w . c d c . g o v / d r u g r e s i s t a n c e / p d f /$ national_action_plan_for_combating_antibotic-resistant_bacteria.pdf (Accessed 10 Dec 2017).

4. Centers for Disease Control. Antibiotic/Antimicrobial Resistance. 2017 https://www.cdc.gov/drugresistance/ (Accessed 8 Dec 2017).

5. Health Policy Brief: Antibiotic Resistance. Health Aff 2015.

6. Fleming-Dutra KE, Hersh AL, Shapiro DJ, et al. Prevalence of inappropriate antibiotic prescriptions among US ambulatory care visits, 2010-2011. JAMA 2016;315:1864-73.

7. Centers for Disease Control. Measuring outpatient antibiotic prescribing. $2017 \mathrm{https} / / / w w w . c d c . g o v / a n t i b i o t i c-u s e / c o m m u n i t y /$ programs-measurement/measuring-antibiotic-prescribing.html (Accessed 10 Dec 2017).

8. Grijalva CG, Nuorti JP, Griffin MR. Antibiotic prescription rates for acute respiratory tract infections in US ambulatory settings. JAMA 2009;302:758-66.

9. Weiss AJ, Elixhauser A, Bae J, et al. Origin of Adverse Drug Events in U.S. Hospitals, 2011: Statistical Brief \#158. Healthcare Cost and Utilization Project (HCUP) Statistical Briefs. Rockville (MD), 2013.

10. Barlam TF, Cosgrove SE, Abbo LM, et al. Implementing an Antibiotic Stewardship Program: Guidelines by the Infectious Diseases Society of America and the Society for Healthcare Epidemiology of America. Clin Infect Dis 2016;62:e51-77.

11. Suda KJ, Hicks LA, Roberts RM, et al. Antibiotic expenditures by medication, class, and healthcare setting in the United States, 20102015. Clin Infect Dis 2018;66:185-90.

12. Liao JM, Fleisher LA, Navathe AS. Increasing the value of social comparisons of physician performance using norms. JAMA 2016;316:1151-2.

13. Winickoff RN, Coltin KL, Morgan MM, et al. Improving physician performance through peer comparison feedback. Med Care 1984;22:527-34.

14. Navathe AS, Emanuel EJ. Physician peer comparisons as a nonfinancial strategy to improve the value of care. JAMA 2016;316:1759-60.

15. Meeker D, Linder JA, Fox CR, et al. Effect of behavioral interventions on inappropriate antibiotic prescribing among primary care practices: a randomized clinical trial. JAMA 2016;315:562-70.

16. Gerber JS, Prasad PA, Fiks AG, et al. Effect of an outpatient antimicrobial stewardship intervention on broad-spectrum antibiotic prescribing by primary care pediatricians: a randomized trial. JAMA 2013;309:2345-52.

17. Centers for Disease Control. Antibiotic prescribing and use. 2017 https://www.cdc.gov/antibiotic-use/ (Accessed 10 Dec 2017)

18. Harris AM, Hicks LA, Qaseem A. High Value Care Task Force of the American College of Physicians and for the Centers for
Disease Control and Prevention. Appropriate Antibiotic Use for Acute Respiratory Tract Infection in Adults: Advice for High-Value Care From the American College of Physicians and the Centers for Disease Control and Prevention. Ann Intern Med 2016;164:425-34.

19. Gonzales R, Bartlett JG, Besser RE, et al. Principles of appropriate antibiotic use for treatment of nonspecific upper respiratory tract infections in adults: background. Ann Intern Med 2001;134:490-4.

20. Centers for Disease Control. Antibiotic prescribing and use in Doctor's Offices. 2017 https://www.cdc.gov/antibiotic-use/ community/materials-references/print-materials/index.html (Accessed 10 Dec 2017).

21. Giguère $A$, Légaré $F$, Grimshaw $J$, et al. Printed educational materials: effects on professional practice and healthcare outcomes. Cochrane Database Syst Rev 2012;10:CD004398.

22. Gjelstad S, Høye S, Straand J, et al. Improving antibiotic prescribing in acute respiratory tract infections: cluster randomised trial from Norwegian general practice (prescription peer academic detailing (Rx-PAD) study). BMJ 2013;347:f4403.

23. McNamara P, Shaller D, De La Mare D, et al. Confidential physician feedback reports: designing for optimal impact on performance. In: Quality AfHRa, ed. AHRQ, 2016.

24. Asch SE. Opinions and social pressure. Sci Am 1955;193:31-5.

25. Redelmeier DA, Tversky A. Discrepancy between medical decisions for individual patients and for groups. N Engl J Med 1990;322:1162-4.

26. Tversky A, Kahneman D. The framing of decisions and the psychology of choice. Science 1981;211:453-8.

27. Ubel PA, Asch DA. Creating value in health by understanding and overcoming resistance to de-innovation. Health Aff 2015;34:239-44.

28. Fleming-Dutra KE, Bartoces M, Roberts RM, et al. Characteristics of primary care physicians associated with high outpatient antibiotic prescribing volume. Open Forum Infect Dis 2018;5:ofx279.

29. LaPlante K. C.A.B. International. Antimicrobial stewardship: principles and practice. Wallingford, Oxfordshire; Boston, MA: CABI, 2017.

30. Cohen AL, Budnitz DS, Weidenbach KN, et al. National surveillance of emergency department visits for outpatient adverse drug events in children and adolescents. J Pediatr 2008;152:416-21.

31. Shehab N, Patel PR, Srinivasan A, et al. Emergency department visits for antibiotic-associated adverse events. Clin Infect Dis 2008;47:735-43.

32. Field TS, Gilman BH, Subramanian $\mathrm{S}$, et al. The costs associated with adverse drug events among older adults in the ambulatory setting. Med Care 2005;43:1171-6.

33. Tamma PD, Cosgrove SE. Addressing the appropriateness of outpatient antibiotic prescribing in the United States: an important first step. JAMA 2016;315:1839-41.

34. Burton MM, Hope C, Murray MD, et al. The cost of adverse drug events in ambulatory care. AMIA Annu Symp Proc 2007:90-3. 